\title{
Research on Art Education in Rural Primary Schools under the Concept of SPOC
}

\author{
Shaohua Nie \\ Elementary Education College of Linyi University, Linyi, Shandong Province, China
}

Keywords: SPOC concept, rural primary school, art education.

\begin{abstract}
The shortage of teachers is the key problem which restricts the development of art education in rural primary schools. SPOC is a typical curriculum paradigm in the "post MOOC era". Its basic idea is to design and utilize excellent MOOC resources, in order to change or reorganize school teaching process, to promote blending teaching and participatory learning, and to improve the quality of learning and teaching. Under the guidance of SPOC concept, SPOC teaching team is set up to design and develop teaching resources like micro videos. In class, teachers use micro videos to teach relevant contents; cooperative inquiry is realized between students and teachers. After class, personalized learning and communication between students are realized through SPOC platform. Through this model, part-time teachers are able to teach art lessons professionally. It makes up the shortcoming of insufficient art teachers in rural primary schools, and solves students' problem of lacking professional guidance after class. It expands the span of space and time for rural students, and improves the teaching quality of art curriculum in rural primary schools.
\end{abstract}

\section{Introduction}

Art education, as an important part of school education, plays a special role which cannot be replaced by other disciplines. It enriches students' temperament, improves students' moral quality and cultivates their taste. It is a powerful way to promote the development of students' intelligence, as well as the all-round development of their physical and mental health.

With the deepening of quality education and the promotion of basic education curriculum reform, art education has received unprecedented attention and has made great progress. However, in many rural primary schools, art education is still the soft spot; there is still a major gap between urban and rural primary schools. According to survey results, in F county, with the increasing attention and input on art education in recent years, the equipment and facilities required for art education can basically meet the teaching needs, but the shortage of teachers is the key problem which restricts the development of art education in rural primary schools. Art teachers serve as the chief executive of school art education, and are closely related to the success of art education. Uneven distribution of teachers, the lack of professional teachers, and non-professional part-time teachers who do not have high culture levels, are key problems in the art education process of rural elementary schools.

\section{The Necessity and Feasibility of Implementing SPOC Teaching Mode in Rural Primary Schools}

\subsection{Analysis of necessity}

To solve problems exist in the popularization of art education in Beijing, professor Bi-heng Guo from the School of Arts and Communication of Beijing Normal University mentioned that, the insufficient art education condition is not only reflected in the lack of full-time art teachers in class, but also reflected in the lack of qualified teachers after class. He suggested that online learning method could be used to solve this problem. However, Dr. He-qing Huang, who graduated from the department of psychology, Peking University and now serves as a lecturer at the College of Preschool Education, Capital Normal University, mentioned that the Internet can realize the sharing of 
education resources, but it cannot solve all the problems of education. "MOOC" is delicate and exquisite, but it cannot replace the interactive classroom teaching. The problem of lacking in art education teachers cannot be solved.

SPOC is a typical curriculum paradigm in "post MOOC era". It adopts blending teaching method, and realizes the organic integration of MOOC and traditional classroom teaching. It effectively makes up for the shortcomings of lacking in teaching interaction and communication of MOOC, and represents the development direction of MOOC. Its basic idea is to design and utilize excellent MOOC resources, in order to change or reorganize school teaching process, to promote blending teaching and participatory learning, and to improve the quality of learning and teaching. Under the guidance of SPOC concept, SPOC teaching team can be set up to design and develop micro video teaching resources. In class, teachers can use micro videos to teach relevant contents; cooperative inquiry can be realized between students and teachers. After class, personalized learning and communication between students can be realized through SPOC platform. Through this model, part-time teachers are able to teach art lessons professionally. It makes up the shortcoming of insufficient art teachers in rural primary schools, and solves the problem of lacking in professional guidance after class. It expands the span of space and time for rural students, and improves the teaching quality of art curriculum in rural primary schools.

\subsection{Analysis of feasibility}

With the development of educational informatization and the balanced development of compulsory education, rural primary schools in F county have realized the interoperability among classes, schools and schools; the education metropolitan area network has begun to take shape. Micro classrooms and studio classrooms constructed in rural primary schools, together with multifunctional one-touch machines, provide the network basis and material guarantee for the smooth implementation of SPOC teaching mode.

Through many rounds of "national training" and "rural teachers support plan", the levels of information-based teaching of rural primary school teachers has been significantly improved. Teachers are able to design micro class teaching resources, and can use the network teaching platform as well as one-touch machines in multimedia classrooms. It provides personnel and technical assurance for the smooth implementation of SPOC teaching method.

\section{The Design of SPOC Teaching Mode on Art Education in Village Primary Schools}

\subsection{Theoretical basis}

Mastery Learning. The so-called "Mastery Learning", means that under the guidance of "all students can learn well", collective teaching method is used and complemented by regular and timely feedback. Individualized help and required learning time are provided for students, in order to help almost all of the students to master almost all of the contents. Primary school SPOC art education mode means under the guidance of this theory, collective teaching is achieved by using micro videos. It expands the span of space and time for rural students, and helps to realize the cooperative inquiry between students and teachers. Through timely feedbacks on line and off-line, primary school students can master the knowledge of art education. Zone of proximal development. The theory of "zone of proximal development" proposed by Vygotsky, a social constructivism scholar, provides effective theoretical supports for art education in primary schools under the concept of SPOC. The "zone of proximal development" of a student is the difference between the current level and the potential level of development. Rural primary school students come home after school, while their parents are lack of ideas and professional capacity to tutor them in art curriculum. So it is difficult for students transit from current level to the potential level of development. With the help of network interactive platform and the implementation of SPOC online teaching, we can achieve the deep mining of knowledge and the development of learning ability. The method helps students the solid foundation, improve their learning abilities, and improve their levels of learning. The role of "scaffolding" can be better played. Constructivism. Constructivism holds that, "knowledge cannot be 
acquired by teachers' imparting; knowledge are acquired through learners' meaning construction process in certain contexts, with the help of teachers, learning partners and learning resources." Primary school art education under SPOC concept is the teaching process based on Constructivism theory. Using modern information technology and network teaching platform, the teaching environment of primary school art education is established through the integration of teaching resources and high quality micro videos. Through the interactions and cooperative inquiry between teachers and students, primary school art education is realized.

\subsection{Building a teaching team}

SPOC era is an era of team teaching. The whole process of SPOC teaching involves curriculum design, curriculum teaching, recording, video production and editing, group discussion, teacher-student interaction, online learning and communication, as well as learning evaluation. One teacher cannot complete these tasks alone. Therefore, teaching teams must be built to realize the SPOC art education in rural primary schools.

A SPOC art teaching team should be built first. The directors of art teaching and research offices at city (county) levels can be hired as guiding experts; some IT teachers can serve as technical advisors. Teaching and research staff at the art education department of center primary school serve as the head of the team; all other art teachers serve as team members. Collective lesson preparation and research activities are organized to help teachers design SPOC teaching resources together. The group should play its functions and train part-time teachers. Part-time teachers' professional levels and teaching abilities should be gradually improved. Team members cooperate with each other and complete the task of art education in rural primary schools.

\subsection{Designing and developing teaching resources}

In the early stage of SPOC blending teaching, the most important work is to design and develop teaching resources. The design of teaching resources directly determines the depth and scope of students' learning contents. Each learning resource should be carefully chosen and designed by the teaching team. In view of the current situation of primary school art teaching in rural areas, the learning resources of SPOC course are mainly micro courses. The purposes of designing micro courses are, to help part-time and full-time teachers in classroom teaching, and to help students in personalized deep learning after class. Thus, according to the psychological and cognitive characteristics of primary students, as well as teaching goals and the requirements of classroom teaching, the teaching content is divided into a number of knowledge points. Through targeted design, the knowledge point can be explained thoroughly in a certain period. Corresponding micro course resources are made and uploaded to the SPOC teaching platform.

\subsection{Constructing SPOC teaching platform}

By using techniques like the Internet, cloud computing and big data, the SPOC teaching platform can be built on the basis of existing rural primary school platform, in order to support the art teaching in class and students' learning after-school. In addition to the module of displaying learning resources, modules like problem feedback, classroom discussion, test, experience and display space should also be designed.

\subsection{The implementation of SPOC blending teaching model}

Before class. Teachers should learn micro courses carefully, clarify teaching objectives, design intentions, teaching steps and teaching strategies, and make necessary modifications and supplements to micro courses according to students' actual conditions. Teachers should also check the network and machine, prepare teaching tools and arrange students to prepare relevant teaching equipments. During the class. The autonomic learning stage. First of all, teachers should take students as the center of learning. According to the purpose and contents of art teaching, teachers need to grasp students' attention in the shortest time, guide them to participate in the learning process and experience the pleasure of art learning. Second, when watching videos, teachers should carefully observe students and grasp their emotional changes. In order to improve the effects of autonomous learning, teachers 
can re-play or slow down the teaching videos according to students' reactions, as well as key and difficult points in teaching. Third, teachers should integrate micro video teaching with traditional teaching. By adding detailed contents, teachers can stimulate students' interests in learning and improve their understanding of learning content.

Group cooperative learning stage. After the display of micro video, teachers need to ask certain questions to guide students to carry out cooperative inquiry learning and classroom activities. First, teachers should group students scientifically; students should be divided into learning groups according to their characteristics and learning abilities. One group should be composed of 3 to 5 members. Second, teachers should put forward to inquiry questions according to the teaching contents of micro videos and students' emotional changes and doubts in the self-learning stage. The difficulty level of questions must be controlled. Through the positive responses of students and the encouragement of teachers, the classroom teaching will be promoted effectively. Third, in the stage of group cooperative learning, teachers should give full play to the role of guider and mentor, and guide pupils to think, cooperate and communicate with each other.

Summary stage. The summary stage is an important link to improve the effect and teaching and learning quality of micro course on art education in primary schools. In this stage, teachers can use micro videos of the autonomous learning stage to further analyze the contents of classroom teaching, to further clarify the key and difficult points, to summarize and analyze group cooperation and research results, and to do intensive teaching, in order to help students to form more systematic and comprehensive understanding on the art knowledge. Then the homework and after class learning tasks should be assigned to expand the time and space of the students' learning, and to integrate on-line and off-line learning process. The efficiency and effectiveness of primary school art education can be realized.

After class. Students can log in SPOC platform to learn independently according to their own situations, or review the micro lesson. They can also search for relevant information according to the micro courses, in order to expand their knowledge scope; they can discuss problems in the feedback and classroom discussion modules; they can do tests and complete teachers' assignments; they can enter the experience and display space to show their homework through pictures, audios and videos. These activities cultivate students' autonomous learning ability, cooperation ability and innovation ability, and ignite their performance desires.

After class, the SPOC teaching team should pay attention to the feedback and discussion modules, and answer students' questions timely. The learning paths of students should be tracked to grasp their learning situations, in order to make professional and proper evaluation on them and provide individual guidance.

After class, teachers should also reflect and make summary according to classroom teaching status. Teachers should establish the concept of lifelong learning with the help of the team, improve their professional levels and modern information technology application abilities, effectively improve their teaching behaviors, and promote the growth of students, so as to improve the quality of art education in rural primary schools to the maximum extent.

\section{Conclusion}

SPOC model of primary school art education establishes the dominant position of students. It helps students to fully display their artistic abilities in classroom, guide them to understand, love and pursue beautify, and teach them to express and create beauty. The artistic accomplishment, imagination and creativity of students are cultivated. The method gradually cultivates students to become all-round development people who can adapt to the needs of the new era.

Teaching team construction under the guidance of SPOC boost the professional growth of teachers. SPOC teaching environment helps teachers to enhance their abilities and to carry out characteristic researches. Thus, teachers can grow rapidly in teaching morality and ethics, as well as professional levels and abilities.

The implementation of art education in rural primary schools based on SPOC concept solves the problems of professional teacher shortage and non-professional part-time teachers, improves the 
teaching quality of art education in rural primary schools, shares high-quality art resources, reduces the disparity of art education between urban and rural schools, and realizes the educational fairness.

\section{References}

[1] S.H. Nie, Research on information technology innovation based on micro classroom curriculum: take information technology class in Linyi primary school as an example, J. The Guide of Science \& Education. 11 (2015).

[2] B. He, Y. Cao, SPOC: teaching process innovation based on MOOC, J. China Educational Technology. 3 (2015).

[3] Y. Shi, The current situation and strategy of implementing art education in rural primary schools, J. Monthly Journal of Survey of Education. 6 (2017). 